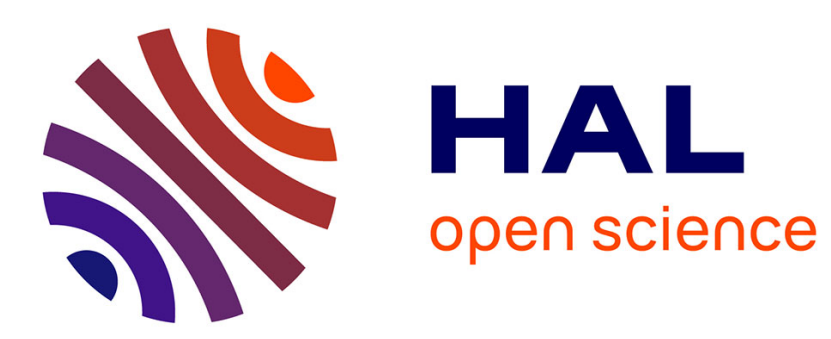

\title{
How the memory of interactions at work makes cooperation complex
}

\author{
Béatrice Cahour
}

\section{To cite this version:}

Béatrice Cahour. How the memory of interactions at work makes cooperation complex. Revue des Sciences et Technologies de l'Information - Série RIA : Revue d'Intelligence Artificielle, 2002, 16 (4-5), pp.517-543. hal-00670590

\section{HAL Id: hal-00670590 https://hal.science/hal-00670590}

Submitted on 15 Feb 2012

HAL is a multi-disciplinary open access archive for the deposit and dissemination of scientific research documents, whether they are published or not. The documents may come from teaching and research institutions in France or abroad, or from public or private research centers.
L'archive ouverte pluridisciplinaire HAL, est destinée au dépôt et à la diffusion de documents scientifiques de niveau recherche, publiés ou non, émanant des établissements d'enseignement et de recherche français ou étrangers, des laboratoires publics ou privés. 


\title{
How the memory of interactions at work makes cooperation complex
}

\author{
Béatrice Cahour
}

CNRS - IRIT/GRIC France

\begin{abstract}
Cooperation in work settings goes through communicative interactions where colleagues need to reach a certain level of mutual understanding for coordinating their actions or finding negotiated decisions. Mutual understanding is complex because of the heterogeneity of the participants which makes the interpretations uncertain and unpredictable. We argue here that chronic cooperation is still more complex because the memory of the previous cooperative interactions is an additional source of difference between the cognitive contexts of the participants. We studied the memory of cooperative interactions in four different collaborative work settings. The analysis indicates a massive forgetting of the verbal content and a greater remembering of the relational positionings, interactional structures and emotions.

$\boldsymbol{R} \boldsymbol{E} \boldsymbol{S} \boldsymbol{U} \boldsymbol{M} \boldsymbol{E}$ Le travail coopératif se réalise à travers des interactions communicatives qui permettent d'atteindre un certain niveau de compréhension mutuelle pour coordonner les actions ou aboutir à des décisions négociées. La compréhension mutuelle est complexe de par l'hétérogénéité des participants qui entraine l'imprédictabilité et l'incertitude des interprétations. Nous posons ici que la coopération chronique est encore plus complexe parce que le souvenir des interactions coopératives précédentes est une source supplémentaire de différence entre les contextes cognitifs des participants. Nous avons étudié le souvenir d'interactions coopératives dans quatre situations collaboratives différentes. L'analyse indique un oubli massif du contenu verbal et un rappel plus aisé des positionnements relationnels, des structures interactionnelles et des émotions.
\end{abstract}

KEY WORDS: chronic interactions, cooperation history, memory, mutual understanding, cognitive context, discursive content, relational positioning, interactional structure.

\footnotetext{
${ }^{1}$ Reference of the article : Cahour B. (2002). How the subjective memory of interactions at work makes cooperation complex. Revue des Sciences et Technologies de l'Information, série RIA, vol.16, nº4-5, 517-543, Numéro spécial "Cooperation and complexity in sociotechnical systems".
} 


\section{Introduction}

We argue in this paper that the complexity of cooperation in work settings where people need to communicate is partly due to the heterogeneity and uncertainty of the interpretation of the verbal exchanges by the participants, and that the memory of the previous exchanges in chronic cooperation increases this complexity.

We will consider the interactional part of the cooperative work and the complexity of reaching some kind of mutual understanding when working together .

Interaction is the core of cooperative work, it is what fundamentally transforms the work from individually performed to cooperatively performed; there is cooperative work when people need to act together, to act with each other, to «interact», and then need to communicate.

Our research focuses on the socio-cognitive dynamics of communicative interactions in work settings, and more particularly on how people, through communication, share a common representation of the problem and situation to be able to cooperate efficiently [CAH 98a] [CAH 98c]. The sharing of a « sufficiently » common representation is very complex.

We already know that there are various levels of mutual understanding and that each participant of a dialogue may interpret the situation and the communicative exchanges in different ways, but we do not know if this difference increases with on-going time and when memory has faded.

One factor which may increase the complexity of the cooperation is that most of the time it is historic, following previous exchanges with the same participants. At work, but not only, most of the interactions are «chronic»: we work and communicate with colleagues during a more or less formal work meeting, and then later on, a day, a week or a month after, we work with them again, on the basis of what we said and did together during the previous meeting. We then suppose a priori that we share a memory of this common interaction that we had jointly.

The objective here is to have a clearer idea of what is recalled of a cooperative interaction after a while, and what is the level of homogeneity between people in this recall. The point is to better know what is the shared memory of the previous interaction in chronic cooperation.

We will show first how communication in itself is a complex process which requires sophisticated interpretation mechanisms from the interlocutors and how mutual understanding is uncertain in this regard. Our point is that there are even more discrepancies between the interlocutors later on, when they meet several days or several months later to continue their collaboration on the basis of the previous verbal interaction; this temporal evolution of the supposed "common ground" (as called by [CLA 91] acquired during the cooperative interaction has not been questioned much and we want to address this issue by analyzing different data concerning the memory of cooperative interactions. 


\section{Heterogeneity, unpredictability and uncertainty in cooperative communications}

When people interact, Schütz [SCH 87] says that they tend to believe from a naive point of view that they are globally identical. This is what he calls "the illusion of reciprocity". This thesis of the reciprocal perspectives states that the common thought goes over the differences of individual perspectives via two basic idealizations: the idealization of the interchangeability of the points of view (the other sees what I see the same way) and the idealization of the congruency of the relevancy systems, which consists in minoring the importance of the biographical differences between oneself and the other.

As stated by Shütz the similarity is only an illusion; each one is unique and differences in behaviour, interpretation, belief, emotion, way of thinking, etc, are enormous, even between the most proximate persons. Consequently, when we communicate, "all sorts of risks are taken, assumptions and guesses are made" [SPE 86] ; we are never sure at which level our interlocutor has understood what we meant, and we never know if we « really » understand what he means. We share a representation at a certain level but this level maybe very low sometimes when we think it is high. Mutual understanding is then uncertain.

Understanding an interlocutor is uncertain first because language is polysemic and its interpretation is situated ; pragmatics has shown clearly how it depends on the context of its production [SEA 69] [MOE 94], especially in the case of indirect speech acts where the illocutionary force varies with the context ; for instance «can you open your book? $\gg$ is an order if produced by the teacher in a class-room but it is a real question about a possibility if produced to someone who has a broken arm.

Possible interpretations are plurial if we look at the detailed interpretation and not just at the very global meaning; the meaning of any utterance is potentially different for every person. For instance, when I say "I would like to speak English fluently", what does it mean for me and for you? will you think I am very far from that? will you think of the reasons why I need to speak English? what will be your representation of 'fluently'? will it be the same as mine ? will it mean for instance : to be at ease to communicate on any topic in this language ? or to talk in a way that one cannot know I am not a native english speaker ? Also the intention meant by «I would like » : will you understand it as «it's one of my priorities and I work hard for that » or «it's an unrealistic dream »? ... We can see with this simple example how what I have in mind when I say these phrases may be far from what you are thinking or have understood.

We can see sometimes disastrous consequences in the variety of possible interpretations in cooperative work. Decortis \& Pecheux [DEC] described how, during a shift change over in a nuclear power plant, the new team misunderstood the following message given by the team about to leave:"the pump is unavailable", and 
then created a pump dysfunction, mainly because of the potential ambiguity of the term « available».

It clearly shows how the ambiguity of a single term may engender important problems in coordination.

We can only have a vague idea of the way the colleagues will grasp a certain representation of the situation at hand or of the discourse we hold. Mutual understanding is then a complex process which is largely imperfect.

"We assume that communication is governed by a less-than-perfect heuristic (...) Failures in communication are to be expected: what is mysterious and requires explanation is not failure but success" [SPE 86].

This uncertainty lets hazard, fuzziness and risk be part of the cooperation, and it complexifies it by the fact that no clear calculation may be done about the effects of our communicative behaviour. The interlocutor remains mysterious and the system formed between the different actors of a cooperative situation is unpredictible. Anticipation is consequently limited.

Another factor which increases complexity is the high interdependance within the actors of a verbal interaction. In a conversation (for instance in work meetings) the change of locutor is extremely rapid and often one has not even finished his/her utterance than the other has begun a new sentence. At each turn-taking, the mental state of each participant is modified and their representation of the cooperative state is then constantly evolving. The system is unstable and constantly changing, each actor undergoing the rhythm of the other and needing to adapt to this unpredictible temporal development.

Heterogeneity and interdependance makes the interaction system globally unpredictible for the observer and for the actors (except in extremely stereotyped situations of interaction). This unpredictability is the core of the complexity of any system showing chaotic behavior [PAV 01].

\section{How the memory of the interactions history increases the heterogeneity in chronic cooperation}

The context is important in the communication process, and the memory of previous interactions is part of the context in chronic cooperation ; consequently the evolution of the individual representations of the interaction after a while will have an effect on the next work meeting; though we observe a lack of studies on this issue of the memory of cooperative interactions.

\subsection{The role of the context in cooperative interactions}


The context is the perception and knowledge used for the communicative purpose, or more generally for the action purpose.

According to Sperber \& Wilson [SPE 86], the dynamic construction of contexts for mutual understanding is conducted by a search for relevance, i.e. by a search for many cognitive effects and few cognitive efforts ; they also proposed the notion of mutual cognitive environment which is larger than the context since it corresponds to what the participants can potentially perceive or infer during the communicative moment.

"A context is a psychological construct, a subset of the hearer's assumptions about the world (...) a context is not limited to information about the immediate physical environment or the immediately preceeding utterances: expectations about the future, scientific hypotheses or religious beliefs, anecdotal memories, general cultural assumptions, beliefs about mental state of the speaker, may all play a role in interpretation" [SPE 86].

We have developed in [CAH 96] this notion of cognitive context in the cooperation dynamics and we showed how the illusion to share a similar cognitive context may lead to misunderstandings in cooperative situations. We defined it as the transitory representations which are constructed or activated during the interaction for the purpose of mutual understanding and decision-making, and which concern :

- the spatio-temporal environment,

- the psycho-social situation,

- the task at hand,

- the previous interactions between the interlocutors ; this last point (that we call here the cooperation memory) corresponds to the memory of what happened during the previous meetings, what were the decisions taken, the solutions proposed, the arguments for negotiating, etc. It is an important part of the context used for communicating during chronic cooperation.

\subsection{Chronic cooperation and memory}

If uncertainty and unpredictability complexify the present of a cooperative interaction, in a following interaction the work of the memory increases heterogeneity and uncertainty.

If the actors reach a sufficient degree of mutual understanding for the needs of the present cooperation, what will remain after a while and will it be enough ?

What is memorized of the past interaction, of the decisions taken in a previous meeting, of the reasons for these decisions, of what was agreed on, of what was argued by the various participants? 
This issue is essential if we consider that cooperation is most of the time made of chronic interactions, that it is developed in large time-spans in a repetitive manner and that it has most of the time a past history that we can call the "cooperative history". This point of view which includes chronicity and then history of a cooperation process necessarily also implies the memorization processes.

Memory is different for each one, first because nobody leaves the same event with the same point of view; differences in life history necessarily lead to differences in memorized information.

It is then legitimate to wonder what will become in the future the common ground which has been built during the interaction. If, as stated by Clark \& Brennan [CLA 91], during a cooperative interaction the contributor and the partners mutually believe that the partners have understood what the contributor meant to a criterion sufficient for the current purpose, what about this grounding criterion in the future? One believes that the partner has understood even if it is not always true, and one tends to believe that the partner will memorize the same way, which is still less probable.

At Schütz illusion of reciprocity we would add that the following cooperative interaction will take place with the implicit and simplificatory hypothesis that the other one has memorized just like we do. This basic hypothesis will function by default, if the other one is not identified as very different.

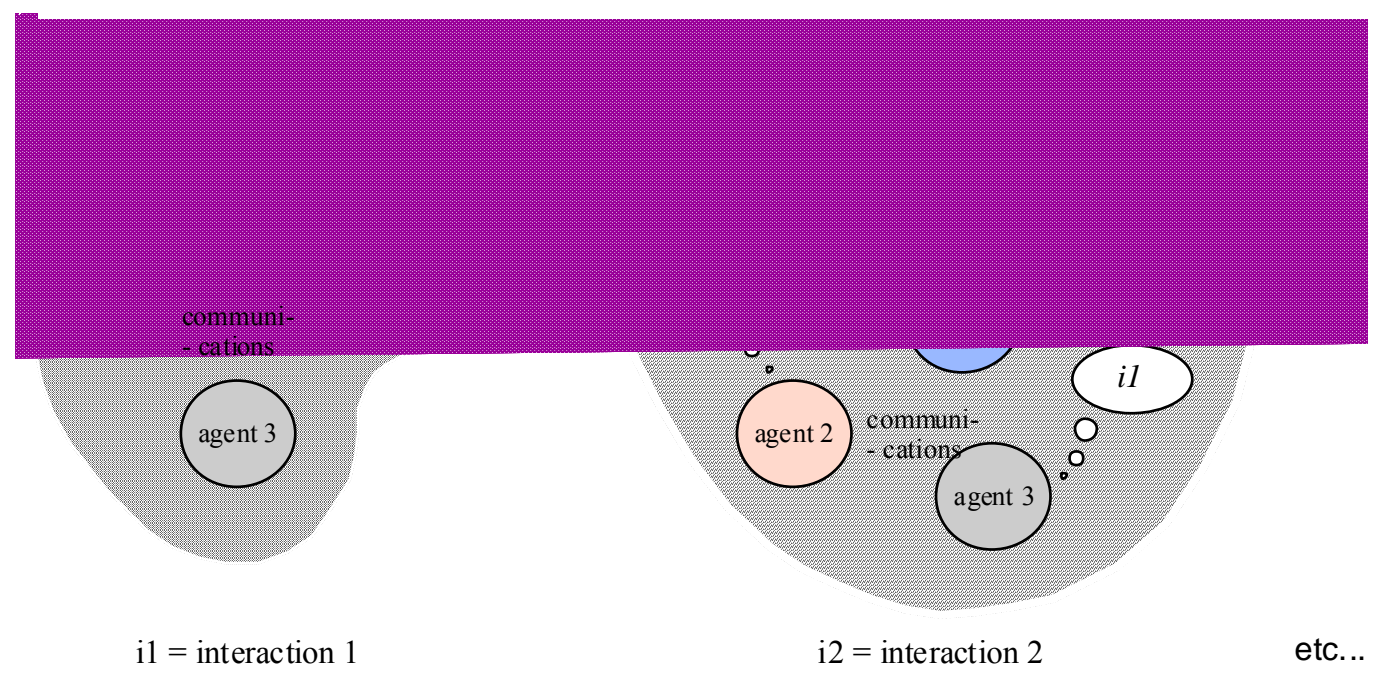

Figure 1. Cooperation history 
This evolution of the information which has been memorized in cooperative interactions has consequences for the studies on Design Rationale [MOR 94]. These studies aim at tracing and storing the history of the decisions taken collaboratively in various projects (often industrial design projects) for reusing previous solutions, for avoiding previous errors or for improving the communication in the team.

\subsection{State of the art}

This issue of the memorization of cooperative interactions has not yet been studied.

Much has been done in the domain of texts memorization which are read by subjects in experimental conditions [DEN 84] and it gives interesting information about the way verbal material is memorized, using scripts [SCH 77], schemata [RUM 75] or story structure [MAN 77] for instance. We can wonder if interaction memory is also helped by some sort of interactional schemata. Though a fundamental difference is that text reading is a solitary activity whereas verbal interaction is a collaborative process ; the subjects are not alone with their mental activity but must also integrate the rhythm of the other and all the surprises of the interaction, all the unexpected which must be dealt with very quickly (like when the other is asking a question, disagreeing, etc) ; in reading a text we have the possibility to manage the time for thinking and re-reading. During an interaction the participants also have to deal with the relational aspect of the situation, the other is physically present and it renders the management of the faces (or social images) necessary for protecting a social harmony [GOF 59], [GOF 67].

Another area which could inform the souvenir of cooperative interactions is the domain of the autobiographical memory, or surveys, where researchers study the way various events are remembered in the long-term [SCH 94]. The difference here is that the events recorded are not verbal interactions and that the level of detail of the recall is generally low: it is for instance the recall of the frequency of engagement in some determined daily activity, like Wagenaar [WAG 86] did, during six years, writing each day two occuring events, precising who was involved, where and when it took place, what happened, and its degree of frequency, emotional implication and agreability ; or the recall of the number of cigarettes smoked, or the dietary habits [SCH 94], which are compared with the actual behavior to observe the memory reliability and the effect of emotions, delays or modes of questioning on this reliability.

But by now we did not find experimental studies looking at what is recalled from an interactional event. 
We know that memorization of past events, interactional or not, is partial; but we do not yet know much about the reasons for this forgetting. Baddeley [BAD 90] presents different possibilities :

- weakening, erosion, degradation of the trace, just like a chain of mountain erodes,

- fragmentation and loss of some elements,

- interference and covering by the following traces

- impossibility of recovering.

Other authors now even reconsider the idea of a mnesic storage of any kind [ROS 88] and propose that the memory is re-constructed each time. The question then remains opened and we will consider here the forgetting process in Baddeley's opened frame.

\section{Case study : memories of collective design of advertisement}

We will develop a study we conducted about the memory of collaborative design dialogs, and we will also mention three other situations where the memory of work interactions is involved. All these situations of cooperation are highly communicative : the verbal exchanges during the work activity are frequent, central for the achievement of the task and not too standardized. 


\begin{tabular}{|c|c|c|c|}
\hline Work situation & Recall delay & $\begin{array}{c}\text { Number of subjects' } \\
\text { recall }\end{array}$ & $\begin{array}{c}\text { Number of } \\
\text { participants in } \\
\text { the interaction }\end{array}$ \\
\hline $\begin{array}{c}\text { slogan design } \\
\text { interaction }\end{array}$ & $10 \mathrm{mn}$ & 18 & 2 \\
\hline idem & 18 months & 11 & 2 \\
\hline $\begin{array}{c}\text { scientific } \\
\text { meeting }\end{array}$ & 8 months & 2 & 9 \\
\hline $\begin{array}{c}\text { administrative } \\
\text { meeting } \\
\text { (Sanchiz) }\end{array}$ & 1 month & 6 & 2 \\
\hline $\begin{array}{c}\text { agent-client } \\
\text { interaction }\end{array}$ & $10 \mathrm{mn}$ & 1 & \\
\hline
\end{tabular}

Figure 2. Characteristics of the situations studied

We studied the immediate and long-term memory of cooperative interactions where people design advertisements. The issue was to know about the evolution of the supposed shared background of chronic cooperation and then to have results about what is the remaining representation of cooperative interactions held by the participants after a while.

\subsection{The corpus : design interactions and interviews}

We needed to get several interactions in rather similar conditions in order to draw some generalizations. The work situation is then «provoked » in the sense that we asked people to cooperate in designing a slogan and, after a while, to remember what happened during this cooperative interaction.

We gathered three types of data in chronological steps :

- The slogan design interactions : nine groups of two students in advertising and communication were asked to design a slogan of one or two lines which satisfied both partners; they interacted by phone (for us to have a focus on verbal interactions), and they did not know the study was about memory of dialogues. The objects to be advertised were either paper-clips, earplugs, umbrellas or cotton buds. The interactions lasted more or less half an hour and were audio-recorded. These 
nine interactions were similar in the task (slogan design), in the type of partners involved (similar level of competency), and in the setting.

- The immediate interviews : in the second step we had immediate interviews with all the participants to study the short-term recall of the design dialogues.

- The delayed interviews : in the third step we performed interviews eighteen months later with eleven of the participants (the others were not available anymore), to study their long-term recall of the design interactions.

All the interviews were audio-recorded and transcribed. We then analysed the remembering of the design dialogues by comparing the recall as observed in the interviews and the effective design interactions.

\subsection{Remembering of the design dialogues}

\subsubsection{Immediate memories of the design dialogues}

After the interaction we conducted immediate interviews with each partner separately, a few minutes after the end of the interaction, and asked them to tell us anything that he/she recovered from this interaction. After this spontaneous recall which consisted in a summary of what they said during the dialogue, they were questioned using dialogue cues to help the memorization with a technic of priming [BAD 90] : the interviewer had listened to the dialogue and taken notes, and could then ask for instance "when you talked about \{concept x $\}$ what did you say?", "what was the reaction of your interlocutor when you said \{utterance y\}", or "who proposed the idea $\{z\} "$ ? (even if the subject had not mentioned yet this concept, utterance or idea).

Finally, more general questions were asked, like "do you think you've had different roles? if yes, which ones?", "have you had any difficulties of mutual understanding or of agreement?".

The analysis (consisting in comparing the interaction and its immediate recall) indicates that, in the immediate recall, almost everything remains accessible by the subjects (not verbatim but rephrased), and the priming cues are very helpul for the recall. The ideas they exchanged during the dialogue and the slogans they found were most of the time easily retrieved. We can observe some lapse of memory but no transformation and imaginary constructions in this immediate recall.

What is told spontaneously by the subjects is the content of the interaction, what they told each other: the topics and ideas they exchanged about the advertisement, the different slogans they proposed and the one they finally chose, the visual scenes they eventually talked about to complement their slogan; sometimes the author, that is the one who proposed the idea, is also spontaneously mentioned. 
The only two persons who had some difficulty recovering the chosen slogan were those who were more passive in finding it, and who, during the interaction, found ideas but not verbal slogans.

With cues helping the memory of the dialogue, the subjects easily retrieved the misunderstandings, the disagreements, the arguments which were exchanged (not verbatim), the author of such or such idea and the role that each participant had during the interaction.

Concerning the author of a proposition (of idea, image, slogan, term...) the subjects sometimes forgot that they were at the origin of an idea, or thought that they were the author when they were not ; in these cases the author, in the rapidity of the verbal exchanges, has become a collective author, a "we have found that together", even if, during the recorded interaction, the author could clearly be identified.

For instance in one of the design interactions, Ann had defended her idea of comparing before and after the use of an earplug but she does not remember it in the short-term recall, and says «I don't know who said that... ».

\subsubsection{Long-term memory of the design dialogues}

One year and a half after the design interaction, eleven subjects had been interviewed again to study the long-term memory of these design dialogues.

A specific methodology of interview has been used because of the difficulty of the long-term recall which necessitates a careful and delicate way of interviewing the person so that the questioning facilitates the access to this distant design interaction, and not entrave too much the delicate mental course that the subject will have to follow to let this past experience come to his mind again. This methodology is the Explicitation Interview ("Entretien d'Explicitation" in french) and has been developed by Vermersch, a researcher in cognitive psychology who develops a phenomenological perspective on human activities [VER 94], [VER 98].

This interview technique aims at accessing and describing the subjective experience of a past activity, mental or externalized. It is based on the principle that the interviewed person is brought in evocation of his past activity and recovers a vivid memory of it ; for that, the interviewer focuses him on his activity at a specific moment in time and space, and questions him about the various sensorial modes of experience (what was heard, seen, felt...). Several other interview techniques are used that were developped in [VER 94], aiming at keeping the subjects in touch with their experience, getting them to describe more completely what was their activity and what happened without influencing their recall (asking for instance opened questions with a minimum of propositional content). The subject recovers then the past experience in a more complete, personalized and detailed manner, not in a distant and abstract way. 
In the second step, when the subject did not recall anything more, we also used the priming technique with cues of the past dialogue (see $§ 4.2 .1$ ).

The interviews lasted between half an hour and more than an hour.

The frame of analysis we used was the following [CAH 98b] ; we differentiated several types of processes :

- a recall, more or less precise, of an element of the past interaction;

- a recognition; with the help of cues of the interaction the person remembers an element of the interaction (verbal proposition, laugh, interlocutor, place...) and can develop it.

- a forgetting; the subject does not, during the interview, remember an element of the interaction when the interviewer asks about it.

- a construction, when the subject adds some element which actually did not happen during the interaction.

The categories of elements that we differentiated as objects of the remembering after a detailed analysis of the data, were :

- the discursive content,

- the authors,

- the structure of the interaction,

- the structure of the slogan,

- the situational context,

- the emotional atmosphere.

The analysis indicates that, eighteen months after the design interaction, these different elements of the interaction are not equally remembered, and that interindividual differences exist. Our presentation will go from the more difficult recall to the less difficult, with several extracts of interviews.

\subsubsection{Massive forgetting of discursive contents and authors}

The interaction element which appears to be the most difficult to remember after this long period of time is the discursive content of the exchanges, that is the topics and ideas developed, the arguments exchanged, the utterances and the lexical items proposed for the slogans.

During the immediate interviews, the discursive content was spontaneously and immediately described by the subjects, but they cannot retrieve it after a while. 
All of them do not remember much of the verbal content of the dialogue at the beginning of the interview, and only some of them finally retrieve some ideas which were developed during the interaction or some parts of the slogan they found. It is mainly this discursive content which leads to inter-individual differences.

We can see below how B recalls vaguely an idea of advertisement that they discussed eighteen months ago, and in the whole interview ${ }^{2}$ he cannot remember more about the content linked to the solution they discussed during their half an hour discussion:

B : « maybe the final slogan he told it, maybe it was me, maybe it was a mix of both... what I know, I know that it was quite funny... that there is a granny, now I think of a granny, well.. we talked about a small girl... also a dialogue between the granny and her granddaughter, but it's vague, really really vague... I could not remember the slogan.. well maybe with a bit of reflection but I 've been thinking about it for a while but no...

I : hmm hmm then a granny and her granddaughter...

B : a dialogue, a conversation between two persons, I'm quite sure about that ».

Actually, for designing their slogan for cotton buds, they discussed about having a mammy discussing with a small child (it was a boy) and who could not hear him.

The following example indicates that an idea which was largely developed during the creative dialogue (A said «I think also of a tramp » and then B was imagining a scene where there was a tramp who was entering in a supermarket, not to buy wine but cotton buds for cleaning his ears) is not at all accessible anymore, not even by recognition when the interviewer, at the end of the interview, says it again:

I : «would you have talked about a tramp, a down-and-out?

B : well it doesn't remind me of anything, no I don't think so... (in a low voice) a tramp...»

We observed that the cues in the dialogue are very helpful in a short-term recall but generally not in a long-term recall; though in the following example, an exception occurs and, after a long interview without any recall of the discursive content, three slogans are proposed to the subject who recognizes, through a feeling of familiarity which surprises him, the one they actually found during the interaction.

\footnotetext{
${ }^{2}$ All the extracts of interviews and dialogues are translated from french.
} 
I (proposing three possible slogans) : " 'for a quite and sane sleep, use the earplugs $X$ ' ... 'for a silent and sane sleep, use the earplugs $X$ ' ... 'for an easy and quite sleep, use the earplugs $X^{\prime}$ '..

$\mathrm{A}$ : it would be rather 'quite and sane'

$\mathrm{I}$ : rather 'quite and sane'...

A : yes (silence) I would be more inclined to this one well (silence) I don't know ; I find it more familiar than the others... but it's not at all what I had in mind, at least what I thought I remembered, so well...

I : 'silent' maybe ?

A : 'silent' (silence)...no... 'quiet and safe' yes, at least maybe we tried something around this idea.»

We can observe here how the utterances which have been pronounced one year ago may still awaken mental echoes, even when the subject is surprised because he would have waited for another type of utterance, and then does not control what came back.

We only observed two subjects who could have a rather precise remembrance of some of the ideas or words used in the slogan, but only after a long time of interview.

Not only the discursive content of the dialogue is generally forgotten but also the author of the ideas, topics and slogans which were discussed before.

When some content is recalled, its author is generally forgotten and either the subjects only mention the collective author in terms of "we", or they rationally infer who was the author (correctly or not) ; with on-going time, the discourse is recalled as produced collectively with no more differentiation between the partners.

Rationalizations to infer who was the author are the inferences made by the subjects based on their knowledge of the partners (their tastes, their tendencies...) to find out who was the author of an idea. As described by [GRU 97], the trace in memory of the signs and of their meaning has faded, and one tries to assign this trace to a locutor, on the basis of the cues that it conveys.

The representation of the partners leads to an inferential recovery [HER 94] and it is a very different process from a direct recovery. These inferential recoveries are a source of error because then the subject hasn't a vivid memory of the event but makes a rational hypothesis about its probable development.

\subsubsection{Remembrance of the structure of the interaction and slogan}

The verbal content of what was said during the interaction is generally forgotten but we observed a much more frequent remembrance of the structure of what was 
said eighteen months ago: structure of the slogan and pragmatic structure of the interaction.

Sometimes, the subject does not recover the verbal content of the slogan but he/she can recall, as below, the structure of the slogan, its rhythm, its length, etc. For instance :

I : (I suggest a possible slogan) « do you think you found that ?

B : no no no, no, not that at all

I : not at all, it's not at all what you found?

B : no no not at all... it was rather long, it was...

$\mathrm{I}: \mathrm{hm} \mathrm{hm}$

B : yes, it was... I don't know... it was not, it was not a a phrase of three or four words, it was at least five or six. »

This recall of the form of the slogan is correct since the effective slogan was 'the noise annoys you, take your earplugs with you' ${ }^{3}$.

The memory of the interactional structure is particularly striking; it is often recalled and corresponds to the structural development of the design interaction, with a description by the subjects of :

- moments when they got blocked on a fixed idea,

- or conflictual moments when they disagreed,

- or the type of evaluation they gave an idea,

- or the number of slogans proposed and the rhythm of the propositions,

- or the way they reached an agreement and concluded.

These interactional structures are remembered independently of the verbal content of the exchanges and if we asked the subjects what they disagreed on, or which was the idea on which they got blocked, they are unable to answer.

This « interactional structure » corresponds generally to the temporal succession of moves as they were described by [SIN 75] or "big speech acts" ([SEA 92] defines them as being composed of several basic speech acts, and gives the example of a justification) linked to the design task (like proposal or absence of proposal, justification, positive or negative evaluation, etc); the actor ${ }^{4}$ of this kind of illocutionary act is often specified but its propositional content is forgotten.

\footnotetext{
3 in french : 'le bruit vous agace? emportez vos boules Quiès!'

${ }^{4}$ We see how the author of a verbal content is often forgotten whereas the actor of an illocutionary act is more often remembered.
} 
B : «I think that we proposed something and then well... we stayed one or two minutes saying "yes yes yes maybe it's okay », and then actually we probably did not find anything better and during/ we needed at least one minute each to say that once more it was okay, and that we will stop there »

This is correct since the dialogue ended with the two women expressing their moderate enthusiasm by phrases like : «it's not that bad («ça peut se faire » in french)..... anyway by now we couldn't find something better... it's more or less correct » during twenty turn-takings.

In the two following extracts, the subjects describe how they had a fixed idea that their partner did not like, but they cannot describe the content of the utterance or of the idea:

A : «we proposed many things, well, me and her, but some of the ideas did not work.. I think that I had a rather fixed idea of something I had set my heart on, let's say that I considered judicious, we discussed about it but I can't remember what it was about

\section{$\mathrm{I}:$ it was more an image or it was more/}

A : no it had to do with words which... she proposed something else and she was trying to convince me that it was not good (...) me I was also trying to convince her (...) well it has been rather brief, after we went on something else and then we proposed several things connected to the previous situation where I had an idea that suited me but less Nathalie, then there was that and after we had maybe, well, four proposals and we kept one of them... but sometimes it was only on parts of utterances, on the beginning... the end suited us but the beginning didn't, or... »

Actually during the dialogue, A had the idea of presenting someone before and after the use of the earplugs but B did not agree and thought it was better to address the slogan only to the people who are nervous; after, B proposed a compromise with the idea of a slogan with a comparison before/after but addressed to nervous people ; then A and B proposed several slogans (more than seven in fact) with two parts (before/after) by changing one part or the other and finally chose « not to suffocate to death under your pillow and to spend the night of your dreams, use the earplugs $\gg^{5}$. We recognize in the real dialogue the recall made by $A$ of the interactional structure even if she does not remember the verbal content.

The following extract indicates also a very precise remembrance of the positionings of the two participants (who found a slogan, what was the reaction of the other etc) but with no indication at all about the verbal content.

A : « each time she was giving me an argument, I reflected on it, I was thinking : well yes it's true, maybe she wasn't wrong but... since we had found a

\footnotetext{
${ }^{5}$ In french : 'pour ne pas mourir étouffé sous votre oreiller et passer la nuit de vos rêves, utilisez les boules quiès'
} 
slogan at the start... I think, I'm not sure but I think that it's me who proposed the first utterance... then after we were a bit bloked on this utterance because she, she did not agree, but since it was me who had found it, I was in trouble to get out of this idea, I was in trouble... »

Actually A was clearly blocked on her first idea «the cotton-wool blud, it changes your life ${ }^{6}$ that $\mathrm{B}$ did not find terrific but finally they adopted it because $\mathrm{B}$ could not find any other slogan (A did not help her by the way she was fixed on her own proposal).

The subjects could remember this pragmatic structure which included the positionings, the agreements and conflicts, the roles of each partner and the development of the design solution with the different phases and the global way it happened; but they were most of the time unable of remembering what was the discourse, the arguments, the proposals of slogans, terms or ideas, that is, all the verbal content of the interaction. In Watzlawick \& al.'s terms [WAT 67] the level of the relation is remembered when the level of the content is forgotten. In Searle's terms [SEA 69] the illocutionary acts are more salient eighteen months after the interaction than the propositional content.

Some typical structures of this type of interaction are probably memorized in long-term memory, for instance, in the form of schemata, i.e. organized and memorized structures which integrate our knowledge and anticipations on various aspects of the world [BAR 32], [RUM 75], [SCH 94] they may help the recall of the interactional structures described above : one known schema may be, for instance, that there is someone who proposes an idea or a slogan and then the other agrees or not ; but the fact that they got blocked on a fixed idea is less stereotyped, and in all of the previous examples we could see that they did not remember only a general and stereotyped schema but instanciated schemata with the right variables in it, describing the right chronology, the right actor, etc. It is not general stereotyped schemata which are recalled here but the very specific progress of the past interaction.

The roles, when they are clearly differentiated, are precisely recalled; we can see below how $\mathrm{A}$ and $\mathrm{B}$ (not design partners) recall correctly that their partner was the one who found the verbal slogans and that their role was, for A, to imagine scenes visually and, for $\mathrm{B}$, to evaluate the slogans proposed by the partner:

A: well otherwise it was rather balanced you know. He mainly found the slogans, me I couldn't, well that... and me I was seeing mainly the aspect of the TV advertisement/ I was imagining the avertisement in my head. Well, I was proposing that and after he had a slogan that I loved immediately. It was like that from the beginning to the end.

I : and otherwise, the general impression from this conversation ?

\footnotetext{
${ }^{6}$ In french : « le coton-tige ça vous change la vie »
} 
B : well I know that he found the slogans and me I said if I agreed or not, and why I agreed and why I didn't, we talked about that, we told our opinions

In the following extracts of interviews, $\mathrm{A}$ and $\mathrm{B}$ who were designing the slogan together, correctly remember their asymmetrical roles: A was clearly the leader and did not listen much to B's proposals.

A : I had the impression to lead a bit the interaction... to have succeeded in imposing/ I don't know but, to get my point of view developed

B : we generally agreed but I think I was a bit influenced by what he said, more than the opposite

The recall may also be here facilitated by stereotypical roles of leader and follower in a dialogue but still it is correctly instanciated and in the first example, the complementary roles described are more rare : the verbal slogan producer and the other who visualizes the scene.

\subsubsection{Easy recall of the context and emotional atmosphere}

The basic frame of the interaction (i.e. where was the action taking place, which action was carried out and with who) is easily remembered by most of the eleven subjects; it includes:

- the main task, i.e. the fact that they needed to find a slogan for earplugs, umbrella etc;

- the interlocutor, who was someone they could recognize during the interaction because he/she was in the same section of their technical university;

- the place where they stood during the interaction, the room, the place where they sat.

The emotions and global atmosphere are also the first elements of the past interaction which are easily remembered : the laughs during the interaction or the tension, worry or surprise at the beginning, when the other is perceived as comforting because of the complicity, or as disturbing because of the image he/she can have after the interaction.

B : I thought : oh that's going to be difficult ; when I heard Solene's voice, I panicked less

A : there has been a short period of embarrassment, we did not know each other very well and we were certainly a bit shy... to begin the dialogue it was not so easy... I remember I wondered what she would think of me after.. 


\subsection{Conclusion of this study}

We observed that, immediately after the design dialogue, the subjects report the details of the verbal content, even if they may have already forgotten who was the author of the discourse. In the long-term, eighteen months later, the surprising point is that they have forgotten most of the verbal content of the exchanges but they can remember the interactional or illocutionary structure.

We found inter-individual differences, essentially concerning the recall of the content; some do not remember anything, some remember a bit after a while. Globally the subjects are prudent and they very rarely construct something which did not happen ; they tend to be aware of what they have forgotten.

We must consider the fact that the verbal content may be more difficult to remember than the interactional structure and the roles because schemas cannot help its recall. But we saw that even the priming cues of the dialogue (like « did you talk about topic Y ?») do not help the long-term recollection of the propositional content.

These results, based on eleven subjects remembering, have few quantitative validity even if we observed a homogeneity in the difficulty of recalling the content and inter-individual differences in the quality of the recall ; this study must then be generalized with different types of interactive situations in different work settings. One could also argue that this situation of design interactions is not totally natural for the subjects and that consequently the content which is exchanged about the task is not so important to them; but we will see how we find similar results in situations of real work settings.

\section{Other cases of cooperative interaction memories}

\subsection{Memory of decision-taking and informative meetings}

\subsubsection{Recalls of a scientific meeting}

We also analysed two recalls of another type of cooperative interaction : a large meeting with eighteen colleagues from the same scientific laboratory which lasted two days. The objective of this meeting was to inform the colleagues about the present and future topics of research of each person, and to find common issues and a structuring of the scientific topics developed in the laboratory. At the beginning of the meeting, each of the eighteen members presented their scientific issues in ten or fifteen minutes, and then an informal exchange occured where everyone participated to define the common concepts and the new structuring in two or three main scientific axis. The meeting has been audio-recorded. 
Eight months later, we interviewed two of the participants (that we will call S1 and S2) to study their memory of the meeting, and asked them : « can you tell me what do you recall of this work meeting, anything that comes back to mind : impressions, discourses, feelings, voices, visual scenes, or anything else ». Then we made, like in the previous study, an explicitation interview, followed by the use of priming cues of the meeting.

The analysis of the interviews indicates the following results :

Both of the participants remember the physical context of the meeting, that is the place, the room and, more or less precisely, how were the persons seated around the table.

They also recall the global structure of the meeting : first individual presentations by each of the colleagues, then a discussion to find common topics or notions of the team and, at the end, a discussion to find the topic of the future conference that they will organize.

Concerning the content of the interactions, as we will develop below, S1 retrieves very little of it, when S2 retrieves mainly what he said during the meeting and what were the reactions to his discourse.

But both of the interviewed participants retrieve the intervention of a colleague, even if they give a different (and quasi opposite) meaning and appreciation to this intervention :

S1 was marked by this proposition because he thought it was out of tone and self-centered ; S1 says :

S1 : «Later we discuss the title of the conference and the topic which could be federative, and then his interventions are «we could do a conference on... », then something which is totally only in his own domain, totally specialized, on (says the topic in a few words) 7 ... (laughes) then you see, what is striking it's not that it's not interesting, but it's against the current, the general tendency to find federative topics, his proposal is not at all federative (...) it creates a rupture ! »

Whereas S2 remembers it very differently, as a good proposition which had not much impact whereas it was a research topic shared by everyone :

S2 : «I remember a proposal which was not retained, the one of $\mathrm{Y}$ who proposed a conference on (topic a) ; since we all study (topic a), well, at least as a tool (...) even if we study it with different fields and issues, our common characteristic is that we work, not only but mainly on (topic a). »

\footnotetext{
${ }^{7}$ For respecting the anonymity of the subjects, we erased the precise wordings of the proposals.
} 
Another element that both remembered was the interventions of a new colleague, A, who appeared to intervene a lot and to take an important place in the team.

S1 says :

$\mathrm{S} 1:$ : I remember that he used very respectful terms to describe us (...); then he has been the object of alliances (...) though until then we didn't know how he would position himself; alliances from B, R, F; not G; me too I think, by saying how his proposal was extremely dynamic and how it was interesting for us to look at this type of extremely opened theory. »

Here are the only common memories linked to the verbal content, but still with different points of views on a same event. We will now look at the specific recollectioins or omissions of each subject.

\section{Subject 1}

The utterance that S1 said about A (cf previous extract) is the only verbal content that he can recall of the meeting. He cannot remember the topics discussed after concerning the axis or the conference. He says himself that he does not remember discourses but that he recalls only strategies, positionings, stakes :

S1 : «but you know, that's difficult for me to remember discourses, I rarely recall them ; I remember strategies, positionings, strikes, perspectives, it's often that (...) I remember the strikes, the general progress, some directions, and what will happen after; when $\mathrm{P}$ speaks I think : here actually I think we can work together or: I will propose him that; at the same time I observe the general orientation of the laboratory and how I'm positioned in it. »

When I give S1 prompting cues of the topics which have been discussed as proposals for the conference during the meeting, he describes the uncertainty of his remembering of the exchanged content, and his description corresponds exactly to the process of remembering via inferences that Herrmann [HER 94] opposes to direct remembering. It is striking to notice how the persons we interviewed are most of the time able to distinguish when they have a direct access to the past event and when they rationalize by inferring and associating.

For instance I asked S1 : «do you remember that at some point the group discussed about (topic)» and he answered «yes it could be $\mathrm{Y}$ who proposed that topic »

but then he adds spontaneously :

S1: «here I'm conscious that you ask me about the fuzzier part of my memory, and probably that's where there is a huge gap between what really happened and was said, and what I can remember today; here my thought is more based on the principle of association, so I make associations with the risk that it's very fuzzy ; the logic of association itself is not fuzzy, I do attribute a discourse to such person because he is working on such topic and I can imagine 
that they talked about it at some point... but with the risk to be wrong and trapped by a representation that I already have. »

\section{Subject 2}

Concerning S2, the verbal content he remembers is mainly when he intervened and how the others reacted. He remembers for example three discussions where he was implicated, for instance :

S2: «- There were discussions about the research axis, I remember that at first when we defined axis which I don't remember the precise wording, I found that I was a bit out of that ; well it was my impression ; maybe I was wrong but my feeling was that my work could not be framed in the proposal ; I remember I relaunched the discussion and there were interventions from $\mathrm{T}$, V, etc, so $\mathrm{M}$ and $\mathrm{N}$ also, and we could fix the two axis of the laboratory (..) I remember that I said : «personally, stated like that, these two axes, I don't fit my work easily in these axes »; that was (topic) and something else ; except if we enlarge it a lot ; and after I said that it would not impeed me doing what I'm doing [...] we defined two other axes and like that, for me, it was federative ; what I'm doing may fit in one or the other axis.

- do you remember the axis ?

- no I can't, I told you before, no »

We can see how S2 remembers what is said « around " his interventions in these three examples which correspond to the parts of the interview where he recalls the content of the discussions.

He also remembers some precise wordings of the propositions for the conference, but not much, and like for S1, the prompting cues of the proposals discussed does not help him, there is no recognition of the verbal content.

To conclude, like in the slogan design study, S1 remembers better, after several months, the positionings and argumentative structure of the interaction than the verbal content of the proposals, even if once again in this interactive situation, the goal of the meeting is to find scientific topics, that is, a verbal object (like for the slogan design situation). The exchanges are then motivated and focused on verbal contents but still, these are massively forgotten. Like for the slogan design, we observe inter-individual differences, $\mathrm{S} 2$ remembering more of the discursive content when he was himself active in the discussion. This study also shows the different memory that S1 and S2 have about what was said during the meeting. 


\subsubsection{Sanchiz' study of administrative meetings recalls}

Sanchiz in his study of the dynamics of administrative meetings (Sanchiz, in progress), also found a massive forgetting of the verbal content of the interaction in a natural situation of work with a lower delay of remembering.

He could notice that in the meetings of a documentation service of a large French company (Electricity of France) the participants had, only one month after the meeting, a very partial memory of the content of the discussions. These meetings occured every month, but the last one before the meeting studied was three months ago. In the meeting studied, nine participants were informing each other and solving problems by taking decisions; the director of the meeting was the director of the service and she was organizing the exchanges.

Thirty three different topics have been discussed during the meeting.

Six of the participants have been interviewed one month later and asked about the topics which were discussed during the meeting ; they could only mention one, two or three of them; the one being the most remembered was the new place where they should work in the near future.

This study indicates how the content of the discussions in this natural work setting may be rapidly forgotten since the meeting was only one month before the recall (a typical delay between these administrative meetings); most of the participants were active in the discussion in taking a decision, but still they cannot remember the most global units of the verbal content, that is, the topics (which is more global than the arguments or information exchanged on each topic).

\subsection{Distorted memory of an agent-client interaction}

We will describe now a case which indicates how, immediately after the interaction, a participant may have a very distorted representation of the past dialogue.

In a study about the mutual understanding of agents advising clients on financial products at LaPoste and AXA [CAH 98a], the interactions between the agents and the clients were audio-recorded and the agents were interviewed just after the interaction. In one of the interviews we can see how the memory of the agent transforms the collective event.

In the following post-verbalization, she talks about a misunderstanding which, according to her memory of the event, occured during the interaction with her client because she thinks she did not answer the client's question but continued to develop her argument on another topic. 


\section{Interview of the agent}

Agent : "-... to one question I replied something else to her, on the subject of tax reductions, I said to her "you put 4000F" and all, and I talked about product $\mathrm{V}$, and at one point she said to me "how long does it last?", so she stuck with tax reduction and I continued with product V, I saw that I had disconnected, I continued with what I wanted to say to her, and all of a sudden I said to myself "she's talking to me about something else", and I even ask myself if I replied to her once I had finished (laughs), I just carried on regardless (...) I don't know if she realised it, I haven't a clue, perhaps she did all the same since she followed her own line of reasoning so she must have/ I don't know whether she mightn't have said to herself "oh goodness me what's she talking to me about, that's not what I asked her for", perhaps she realised it (louder) yes because when I came back to it afterwards, when I said to her "yes but it's during 8 years", she said to me "yes, that's what I was asking you" (she laughs) so it's true that..." (she laughs) ...

She then has this representation of a misunderstanding which was due to her imperfect listening and she feels at fault.

In fact, when we look at the actual dialog we see that her representation is very distorted and subjective, since there was no misunderstanding at all : in the real dialogue, the agent was talking about the tax cuts when the client asked a question about the product $\mathrm{V}$ and the agent answered her almost instantaneously. In her recall she believes that she changed the subject with product $\mathrm{V}$ and while the client asks a question about the tax cuts she does not answer her, or answers later.

How can we explain this distorted memory of the agent? We may propose three hypotheses, but her memorization process will remain unobservable :

$1^{\circ}$ - this client intervened very rarely and during the whole interaction only asked three questions; maybe the agent retained this question as a sign of understanding difficulty from the client.

$2^{\circ}$ - a phone call interrupted the dialog at this phase; maybe the agent remembered from this interruption a feeling of a break, of a gap.

$3^{\circ}$ - the agent was not completely at ease with this situation of recorded dialogs and follow-up interviews; she was not very self-confident and was consequently a bit reluctant to do the study; when we ask her if there has been any difficulties with mutual understanding during the interaction, a vague feeling of probably having failed could be sufficient for her mind to reconstruct the dialog in this way. This would thus show how the memory process of an emotive person can transform what actually happened.

The main observation is this enormous gap between the reality of the recorded dialog and the subjective representation that the agent has built of what happened 
during the interaction. It is most improbable that the client has a memory of the interaction reconstructed in the same way as the agent. Though we would not like to generalize this result since we saw in the slogan design study that reconstruction and distortions are not so frequent. This case is just a nice example of the way the immediate recall may be a transformation of the reality of the cooperation. We can also assume that the explicitation interviews used for the slogan design and the scientific meeting (but not for this agent-client interaction) avoid the recall distortions by helping the subject to recall progressively and vividly the past situation.

\section{Conclusion}

Mutual understanding and decision-making are central in cooperation and are complex because of the uncertainty of mutual understanding and the unpredictability of the others' behaviour. The complexity increases with chronic cooperation, when people work together regularly, since the memory of the cooperation history is susceptible to augment the heterogeneity between the actors, the differences between their cognitive contexts.

The issue was here to look at the memory of cooperative interactions in different situations and with different delays : what is recalled and by who?

The surprising result is the easy recall of the discursive content of the interaction in a very short delay, and the near impossibility to recall it after a long delay: even if we observed some inter-individual differences, not much of the content was retrieved, and only after a long and cautious interview. The relational dynamics of the interaction (positionings, roles, interactional structure...) and the emotional context are more easily recalled than the verbal content.

We have already stressed the importance of the «interactional positionings » in the dynamics of cooperative design decisions [CAH 98c], that is the roles and attitudes concerning our engagement and position, and this study indicates that they are still accessible after a long temporal delay.

The difficulty to retrieve the verbal content does not seem to be linked to the cognitive treatment during the cooperative interaction, but more to the long-term recollection since in the design dialogs, the subjects, just after the interaction, recall a lot of the verbal content

One explanation of the fact that the verbal content is difficult to remember may be that schemas cannot help its recall. We cannot anticipate the on-going course of a verbal interaction. We saw that even the priming cues of the dialogue, like « did you talk about topic Y ? », do not help the long-term recollection of the propositional content (but it helps the short-term recall). 
Still the fact that the interactional structure and positionings are better recalled indicates that they are salient and important during the interaction since the salient events are generally better recalled [BAD 90]. Though, studies on cooperative processes often ignore this important social and identitary dimension of any work situation.

It is important to notice that the subjects are aware of their forgettings and do not invent a new verbal content, at least when we use a specific interview technique. The subjects rarely construct something which did not happen (except the example of the agent, but it was a classic interview). They tend to be aware of what they have forgotten. For instance S1, when he tends to recover inferentially, to find a plausible memory, knows that he is doing that. We can consider this consciousness of the memory limits and accuracy as a meta-memory ability, but we insist on the importance of the mode of questioning: the more the subjects' memory is questioned in a very direct and rapid way, the more they will tend to rationalize and recover inferentially. The methodology of interview is crucial and tricky for obtaining reliable results, and the point is not to influence the memory course in a sense or another. The explicitation interview technique [VER 94] allows the interviewer to follow the subject's episodic memory.

The conclusion we can draw for Design Rationale is that tracing the design decisions must be done as soon as possible after the design meetings (or better during the meetings) if one wants to have a reliable recall of the verbal content exchanged. Hoping to get participants recalling the verbal exchanges of meetings which took place several months ago seems unrealistic.

We focused here on the complexity of communicative processes in cooperative interactions, on the heterogeneity and discrepancies which make it impossible to anticipate and to model because of the various factors influencing the course of an interaction. For cooperating efficiently, people need to know what is the limit of their common ground and to forget the illusion of reciprocity; the difficulty to remember the verbal content of the interactions increases the difficulty to have a precise idea of the common ground, and people working together would probably gain in being aware of these potential discrepencies and in avoiding the illusion of reciprocity when cooperating.

\section{Bibliography/References}

[BAD 90] BADDELEY A., Human memory, theory and practice, Lawrence Erlbaum ass., East Sussex, 1990.

[BAR 32] BARTLETT F.C., Remembering, Cambridge university Press, 1932.

[CAH 98a] CAHOUR B., Interunderstanding and subjectivity in commercial dialogues, Dialogue Analysis VI, IADA'96 Proceedings, Max Niemeyer Verlag, Tübingen, 1998. 
[CAH 98b] CAHOUR B. , Mémoires d'interactions verbales coopératives : qu'advient-il de Soi et de l'Autre ? Cahiers de Praxématique, numéro spécial L'Autre en Discours, 1998, 445 466

[CAH 98c] CAHOuR B. \& Pemberton L., When people design : conversational positionings and roles in cooperative design dialogues, Proceedings edited by INRIA : SophiaAntipolis, 1998.

[CAH 96] Cahour B. \& Karsenty L., Contextes cognitifs et dysfonctionnements de la communication, Interaction et Cognitions, vol 1, n4, 1996.

[CLA 91] Clark H.H. \& BRENNAN S.E.,. Grounding in communication, In : Perspectives on socially shared cognition, L.B. Resnick, J.M. Levine \& S.D.Teasley (Eds), American Psychological Association, Washington DC, 1991.

[DEC] Decortis F. \& Pecheux V., Construction of shared representations in nuclear power plant shift changeovers, (submitted)

[DEN 84] DENHIERE D., Il était une fois... compréhension et souvenirs de récits, Presses Universitaires de Lille, 1984.

[GOF 59] Goffman E., The Presentation of Self in Everyday Life. Doubleday, New York, 1959.

[GOF 67] GofFMAn E., Interaction ritual. Essays on face-to-face behavior, Doubleday, NewYork, 1967.

[GRU 97] GRÜNIG B.N., Dialogue et mémoire, Dialogue Analysis V Proceedings, Tübingen, Max Niemeyer Verlag, 1997.

[HER 94] HERRMANN D.J., The validity of retrospective reports as a function of the directness of retrieval processes, in : Schwarz \& Sudman (Eds) : Autobiographical memory and the validity of retrospective reports, New-York, Springer-Verlag, 1994.

[MAN 77] MANDLER J. \& JOHNSON N.S., Remembrance of things parsed : story structure and recall, Cognitive psychology, 9, 1977, p. 111-151.

[MOE 94] MoESChler J. \& Reboul A.,. Dictionnaire encyclopédique de pragmatique, Seuil : Paris, 1994.

[MOR 94] MORAN T.P. \& CARROLl J.M.,. Design rationale : concepts, techniques and use. Hillsdale, N.J : Erlbaum, 1994.

[PAV 01] PAVARD, B., Complexity Paradigm as a framework for the study of Cooperative Systems, In Salembier P. \& Benchekroun, T.H. : Cooperation \& Complexity, Hermes, 2001.

[ROS 88] RosENFIELD I., The invention of memory, a new view of the brain, Basic Books, Inc., Publishers, New-York, 1988.

[RUM 75] RumelhaRT D.E, Notes on a schema for stories, in D.G.Bobrow \& Collins A. (Eds) : Representation and understanding, p.211-236. New-York : Academic Press, 1975.

[SAN] SANCHIZ F. De la formation du groupe à sa dissolution; analyse de productions d'écrits et d'interactions verbales de collectifs en entreprise, Doctoral dissertation, University of Rouen, in progress. 
[SCH 77] Schank R.C. \& AbELSON R., Scripts, plans, goals and understanding, Hillsdale, N.J. : Erlbaum, 1977.

[SCH 87] SCHÜTZ A., Le chercheur et le quotidien, Méridiens Klincksieck, Paris, 1987.

[SCH 94] SChWARz N., Sudman S., Autobiographical memory and the validity of retrospective reports, Springer-Verlag, New-York, 1994.

[SEA 69] SEARLE J.R., Speech acts: an essay in the philosophy of language, Cambridge university, 1969.

[SEA 92] SeARle J.R., Conversation reconsidered. In: Searle J.R. et al : On Searle on conversation. Amsterdam; John Benjamins Publ.Cie, 1992.

[SIN 75] SinclaiR J. \& CoulthaRd R.M., Towards an analysis of discourse : the english used by teachers and pupils, Oxford Univ. Press, 1975.

[SPE 86] SPERber D. \& Wilson D., Relevance. Communication \& Cognition., Blackwell, 1986.

[VER 94] VERMERSCH P., L'entretien d'explicitation, Paris, ESF, 1994.

[VER 98] Vermersch P \& MAurel, Pratiques de l'entretien d'explicitation, Paris, ESF, 1998.

[WAG 86] WagenaAR, W.A., My memory : a study of autobiographical memory over six years. Cognitive Psychology, 18, 225-252, 1986.

[Wat 86] Watzlawick P., Beavin J.H. \& Jackson D.D., Pragmatics of human communication, Nex York, Norton, 1967. 